\title{
A STUDY OF PLANTARIS TENDON AND ITS ROLE IN TENDON
} GRAFT

\section{Syed Nazeer Ahmed ${ }^{* 1}$,Pradeep K. Murudkar ${ }^{2}$, Md Khaleel Ahmed ${ }^{3}$.}

${ }^{* 1}$ Assistant Professor, Department of Anatomy, Khaja Banda Nawaz Institute of Medical Sciences, Kalaburagi, Karnataka, India.

${ }^{2}$ Professor and HOD, Department of Anatomy, Khaja Banda Nawaz Institute of Medical Sciences, Kalaburagi, Karnataka, India.

${ }^{3}$ Assistant Professor, Department of Anatomy, Khaja Banda Nawaz Institute of Medical Sciences, Kalaburagi, Karnataka, India.

\section{ABSTRACT}

Introduction: The plantaris tendon has been used in various tendon repairs and also membrane created from stretched plantaris tendon may be wrapped around tendon anastomosis in the Achilles tendon repair.

Materials and Methods: In this study of 50 embalmed lower limbs, average age between $50-60$ years was dissected with standard procedure and various parameters of the plantaris tendon i.e. length, breadth, thickness were measured with the Vernier's caliper and documented.

Results: It has been observed that the mean tendon length was more in male cadavers compared with female cadavers. The total 25 adult cadavers studied of which 23 were males and 2 were females, out of these there were 25 left and 25 right limbs. The plantaris was absent in two limbs and commonest type of tendon insertion was as to the standard study done by previous workers.

Discussion: Glissan in 1932 was the first to utilize the plantaris tendon as a living suture for the repair of gaps in the flexor tendons of the palm, in tendon transplants above the ankle, in repair of a ruptured coracoclavicular ligament, and in repair of a slipping patella by Gallie's technique. The author also mentions that, the plantaris tendon is advantages for the hernia repair as it is having the property of lateral stretching.

Conclusion: It is used as a strong reinforcement membrane and is also useful for surgeons performing various reconstructive surgeries. As the plantaris tendon is a tensile and stretchable structure, it is used as a strong reinforcement membrane after suturing the partial rupture of the Achilles tendon, how far it can be useful for tympanoplasty, clinical trials may be carried out in future by the concerned ENT surgeons

KEY WORDS: Achilles rupture, Plantaris graft, Plantaris tendon, Tendon grafting.

Address for Correspondence: Dr. Syed Nazeer Ahmed, Assistant professor, Department of Anatomy, KBN Medical College, Kalaburagi, Gulbarga, Karnataka, India. E-Mail: nazeer1715@gmail.com

\section{Access this Article online}

\section{Quick Response code}

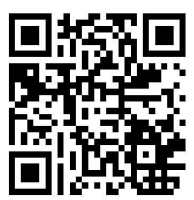

DOI: $10.16965 /$ ijar.2016.521

Web site: International Journal of Anatomy and Research ISSN 2321-4287 www.ijmhr.org/ijar.htm

Received: 29 Dec 2016

Peer Review: 30 Dec 2016

Revised: None
Accepted: 02 Mar 2017

Published (O): 31 Mar 2017

Published (P): 31 Mar 2017

\section{INTRODUCTION}

The plantaris tendon can be stretched laterally and one can convert it into a thin, continuous sheet of tough membrane to wrap around the anastomosis and provide a smooth, strong reinforcement to the suture line[1].The origin of plantaris muscle is from the lateral supracondylar line of the Popliteal surface of the femur just superior and medial to the lateral head of the gastrocnemius muscle as well as from the 
oblique popliteal ligament in the posterior aspect of the knee[2,3,4].The agenesis of the plantaris muscle may affect the dynamics of the knee [5].The muscle belly ranges from $7-13 \mathrm{~cm}$ long varying in its size and form when present, and the mean length of the tendon from its proximal insertion to its distal insertion is 43.25 $\mathrm{cm}[6$,$] .The origin of plantaris muscle is from the$ lateral supracondylar line of the popliteal surface of the femur just superior and medial to the lateral head of the gastrocnemius muscle as well as from the oblique popliteal ligament in the posterior aspect of the knee[7].

\section{MATERIALS AND METHODS}

The plantaris muscle was dissected in 50 adult limbs (46Male and 4Female). After the dissection of the popliteal fossa, Followed by dissection of the superficial compartment of the calf muscles, careful dissection was done for the isolation of the plantaris muscle, the muscle was identified and traced from its origin to its insertion with blunt dissection and when required with the fine dissection keeping other related structures like muscles, vessels and nerves intact fig 01 and 02 shows different pattern of insertions.

Fig. 1:

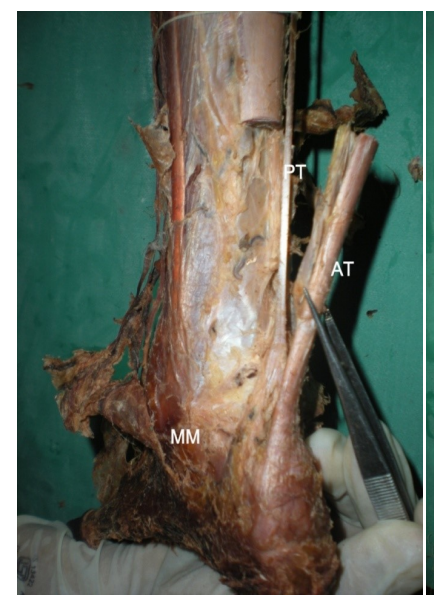

PT: Plantaris tendon, AT: Achilles tendon, MM: Medial Malleolus.

The plantaris muscle was dissected in 50 adult limbs (46Male and 4Female) available in the department of Anatomy KBN Medical college Kalaburagi. Adult cadavers were preserved by the standard method of embalming for the purpose of dissection by the undergraduate medical students.Data analyzed as numbers and mean value. The unpaired t test was used to study the significance of the differences in male and females and right and left plantaris tendon. The length, breadth and the thickness of the tendon were measured Using Vernier's caliper and with the help of thread and measuring scale. The point of measurement taken for the tendon is from the myotendinous junction to its distal attachment.The unpaired $t$ test was used to study the significance of the differences in male and females and right and left plantaris tendon.

\section{RESULTS}

Table 1: describes the mean tendon length, breadth and thickness in the right and left side of cadavers. The dimension of left side tendon in length (32.97 $\pm 7.209,33.36 \pm 7.256)$, breadth

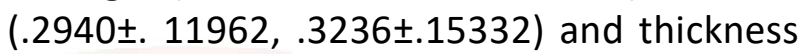
(.056 $\pm .0369, .080 \pm .0951)$ was slightly more on the left side compared with right side and these differences were statistically not significant.

Table 1: Showing the mean tendon length, breadth and thickness in the right and left side of cadavers.

\begin{tabular}{|c|c|c|c|c|}
\hline \multicolumn{2}{|c|}{ Variations } & $\begin{array}{c}\text { Standard } \\
\text { deviation }\end{array}$ & Mean & Significance \\
\hline \multirow{2}{*}{ Total length } & Right & 7.209 & 32.97 & \multirow{2}{*}{0.85} \\
\cline { 2 - 4 } & Left & 7.256 & 33.36 & \\
\hline \multirow{2}{*}{ Total thickness } & Right & 0.0369 & 0.056 & \multirow{2}{*}{0.451} \\
\cline { 2 - 4 } & Left & 0.0951 & 0.08 & \\
\hline \multirow{2}{*}{ Total breadth } & Right & 0.11962 & 0.294 & \multirow{2}{*}{0.451} \\
\cline { 2 - 4 } & Left & 0.15332 & 0.3236 & \\
\hline
\end{tabular}

Table 2: Showing the mean tendon length, breadth and Thickness in male and female cadavers.

\begin{tabular}{|c|c|c|c|c|}
\hline Variations & Sex & $\begin{array}{c}\text { Standard } \\
\text { deviation }\end{array}$ & Mean & Significance \\
\hline \multirow{2}{*}{ Total length } & Female & 0.957 & 30.73 & \multirow{2}{*}{0.032} \\
\cline { 2 - 4 } & Male & 7.43 & 33.38 & \\
\hline \multirow{2}{*}{ Total thickness } & Female & 0.0499 & 0.068 & \multirow{2}{*}{0.991} \\
\cline { 2 - 4 } & Male & 0.0745 & 0.068 & \\
\hline \multirow{2}{*}{ Total breadth } & Female & 0.08539 & 0.3125 & \multirow{2}{*}{0.936} \\
\cline { 2 - 4 } & Male & 0.14115 & 0.3085 & \\
\hline
\end{tabular}

Table 2: Table 2 revealed the mean tendon length, breadth and Thickness in male and female cadavers. It has been observed that the mean tendon length was more in male cadavers compared with female cadavers (33.38 $\pm 7.430,30.73 \pm .957)$ whereas mean tendon breadth was slightly more in female cadavers as compared with males (3085 \pm .14115 , $.3125 \pm .08539)$.The total 25 adult cadavers studied of which 23 were males and 2 were females, out of these there were 25 left and 25 right limbs 
each belonging to the same gender. The differences observed in the morphology of the tendon in the context of gender of cadavers were statistically not significant.

\section{DISCUSSION}

Glissan in 1932 was the first to utilize the plantaris tendon as a living suture for the repair of gaps in the flexor tendons of the palm, in tendon transplants above the ankle, in repair of a ruptured coracoclavicular ligament, and in repair of a slipping patella by Gallie's technique. The author also mentions that, the plantaris tendon is advantages for the hernia repair as it is having the property of lateral stretching [8].The Achilles tendon and the plantaris tendon are enclosed in a common array of thin fibrous tissue, the paratendon containing blood vessels[9].The total mean length of the tendon in this study is found to be $33.16 \mathrm{~cm}$ which is coinciding with the study conducted by Aragao et al in 2010 and with a difference of $2 \mathrm{~cm}$ with Surut et al in 2002[10,11].

\section{CONCLUSION}

It is used as a strong reinforcement membrane and can be useful for surgeons performing various reconstructive surgeries. In such scenario study of morphological characteristics of the tendon is of utmost importance.

\section{Conflicts of Interests: None}

\section{REFERENCES}

[1]. Lynn TA. Repair of torn Achilles tendon, usingthe Plantaris tendon as a reinforcing membrane. J Bone Joint Surg Am 1966;48:268-72.

[2]. Delgado GJ, Chung CB, Lektrakul N, Azocar P, Botte MJ, Coria D, Bosch E, Resnick D. Tennis Leg: Clinical US Study of 141 Patients and Anatomic Investigation of Four Cadavers with MR Imaging and US. Radiology 2002;224:112-119.
[3]. Standring Susan. Gray's Anatomy. The Anatomical Basis of Clinical Practice. $40^{\text {th }}$ Edn. Elsevier Churchill Livingstone, Philadelphia, 2008. pp. 1421.

[4]. Moore KL, Dalley AF, eds. Clinically Oriented Anatomy. 5th ed. Philadelphia: Lippincott Williams \& Wilkins, 2006;648-649.

[5]. A Jay Freeman, Nathan A, Jacobson and Quentin A Fogg. Anatomical variations of theplantaris muscle and a potential role inpatellofemoral painsyndrome: Clinical Anatomy 2008;21:178-181

[6]. Aragao, J A. Reis F P, Guerra D R, Cabral R H. The occurrence of the plantaris muscle and its muscletendon relationship in adult human cadavers. Int. J. Morphol 2010 28(1):255-258.

[7]. Helms CA, Fritz RC, Garvin GJ. PlantarisMuscle injury: Evaluation with MR Imaging. Radiology 1995;195:201-203.

[8]. Glissan D J: The use of the plantaris tendon in certain types of plastic surgery. Australian and New Zealand J Surg1932;11:64.

[9]. Van Sterkenburg MN, Kerkhoffs GM, KleipoolRP, Niek van Dijk C. The plantaris tendon and a potential role in mid-portion Achilles tendinopathy: an observational anatomical study. J Anat 2011 Mar;218(3):336-41.

[10]. Aragao J A, Reis F P, Guerra D R, Cabral R H. The occurrence of the plantaris muscle and its muscletendon relationship in adult human cadavers. Int. J. Morphol., 2010;28(1):255-258.

[11]. Surut J, Ekamol T, Weerachai K, Kimaporn K. Palmaris longus and plantaris tendon: Anatomical variations and relationship, Srinagarind Med. J 2002;17(3):160-163.

How to cite this article:

Syed Nazeer Ahmed, Pradeep K. Murudkar, Md Khaleel Ahmed. A

STUDY OF PLANTARIS TENDON AND ITS ROLE IN TENDON GRAFT. Int J Anat Res 2017;5(1):3572-3574. DOI: 10.16965/ijar.2016.521 